\title{
Correction of Bowleg Deformity in Achondroplasia through Combined Bony Realignment and Lateral Collateral Ligament
} Tightening

\author{
Binu T Kurian ${ }^{1}$, Mohan V Belthur ${ }^{2}$, Stanley Jones ${ }^{3}$, Stephen N Giles ${ }^{4}$, James A Fernandes ${ }^{5}$
}

\begin{abstract}
Introduction: Achondroplasia is one of the most common osteochondrodysplasias with an incidence of 1 in 26,000 live births. Bowing of lower limbs can cause significant morbidity in this population. The use of the llizarov external fixator to tighten collateral ligaments of the knee in children has not been reported in the literature. We report the technique and early results of lateral collateral ligament (LCL) tightening with correction of genu varum in children with achondroplasia.

Materials and methods: A retrospective review of children with achondroplasia presenting with bowleg deformity who were treated by corrective osteotomy and LCL tightening was conducted. Between 1998 and 2003, 12 patients (24 limb segments) underwent this procedure and were included in the study. All patients had grade III LCL laxity preoperatively. Pre- and postoperative anteroposterior standing mechanical axis radiographs were evaluated. The final outcome was graded using the grading system of Paley et al.

Results: All patients had bilateral corrections. The llizarov external fixator was used in 10 patients and the Orthofix limb reconstruction system in 2 patients. The bony realignment was achieved through monofocal or bifocal tibial osteotomies. The LCL was tightened in all limb segments using the Paley's type II strategy. The final result was graded as excellent in 20 limb segments and good in 4 limb segments. One patient developed transient common peroneal nerve palsy, four developed grade II pin site infections, and there was premature consolidation of the tibial regenerate in one patient.

Keywords: Achondroplasia, Bowlegs, Genu varum, Ilizarov, Lateral collateral ligament.

Strategies in Trauma and Limb Reconstruction (2019): 10.5005/jp-journals-10080-1441
\end{abstract}

\section{INTRODUCTION}

Achondroplasia is one of the most common osteochondrodysplasias with an incidence of 1 in 26,000 live births. ${ }^{1,2}$ It is a form of disproportionate short-limbed rhizomelic dwarfism. Characteristic features include relative macrocephaly, frontal bossing, depressed nasal bridge, bowing of lower limbs, flexion deformity of the elbow, dislocation of the radial head, trident hands, and hyperlordosis. It is caused by mutations in the gene that codes for the fibroblast growth factor receptor 3 (FGFR-3) and is transmitted as a fully penetrant autosomal dominant trait. ${ }^{2-5}$ Most cases are sporadic (85\%) and are due to new mutations. At skeletal maturity, the mean adult height is $125-130 \mathrm{~cm}$. There is considerable morbidity and occasional mortality with this disorder such that these patients must be followed closely from birth. Possible problems include stenosis of the foramen magnum and the cervical spinal canal causing cervicomedullary compression with risk of death, central apnea, and neurological dysfunction including paraparesis, respiratory difficulty (from central apnea, a small rib cage and upper airway obstruction), gross motor delay associated with macrocephaly, hydrocephalus, and later-onset neurological problems from lumbar spinal stenosis. ${ }^{2,5,6}$ Hypotonia, genu varum, and joint laxity are common. ${ }^{1}$ In addition, there is frequent otitis media, which may be accompanied by hearing loss and delay of speech. ${ }^{3}$ The effects of short stature and the impact on body image, functional disability, and psychological development are well documented (Figs 1 to 7 ).

Bowing of the lower limbs can cause significant morbidity in this population. Problems with body image, functional disability, knee pain, and the potential for osteoarthritis in adult life are well
1,3-5 Department of Trauma and Orthopaedics, Sheffield Children's Hospital NHS Trust, Sheffield, UK

${ }^{2}$ Department of Orthopedic Surgery, Phoenix Children's Hospital, Phoenix, Arizona, USA

Corresponding Author: James A Fernandes, Department of Trauma and Orthopaedics, Sheffield Children's Hospital NHS Trust, Sheffield, UK, Phone: +447747776618, e-mail: james.fernandes@nhs.net

How to cite this article: Kurian BT, Belthur MV, Jones S, et al. Correction of Bowleg Deformity in Achondroplasia through Combined Bony Realignment and Lateral Collateral Ligament Tightening. Strategies Trauma Limb Reconstr 2019;14(3):132-138.

Source of support: Nil

Conflict of interest: None

documented. The incidence of bowlegs in this population is about $50-60 \%{ }^{3,7}$ Surgical management for bowlegs may be necessary in $20-40 \%$ of children with achondroplasia. The treatment of bowleg deformity associated with achondroplasia is controversial. ${ }^{4,8,9}$ The effects of brace treatment and fibular epiphysiodesis have not been proven. Surgical management of the bowleg deformity with realignment surgery using osteotomies of the tibia and epiphysiodesis of the fibula has been reported. ${ }^{4,10,11}$ Lateral collateral ligament $(\mathrm{LCL})$ tightening as an adjunct to knee realignment osteotomy has been reported previously in a mixed group of patients of varying diagnoses. ${ }^{12}$ The use of the llizarov external fixator to tighten knee collateral ligaments has been described for adults but not for, specifically, children with achondroplasia.

(c) The Author(s). 2019 Open Access This article is distributed under the terms of the Creative Commons Attribution 4.0 International License (https://creativecommons. org/licenses/by-nc/4.0/), which permits unrestricted use, distribution, and non-commercial reproduction in any medium, provided you give appropriate credit to the original author(s) and the source, provide a link to the Creative Commons license, and indicate if changes were made. The Creative Commons Public Domain Dedication waiver (http://creativecommons.org/publicdomain/zero/1.0/) applies to the data made available in this article, unless otherwise stated. 

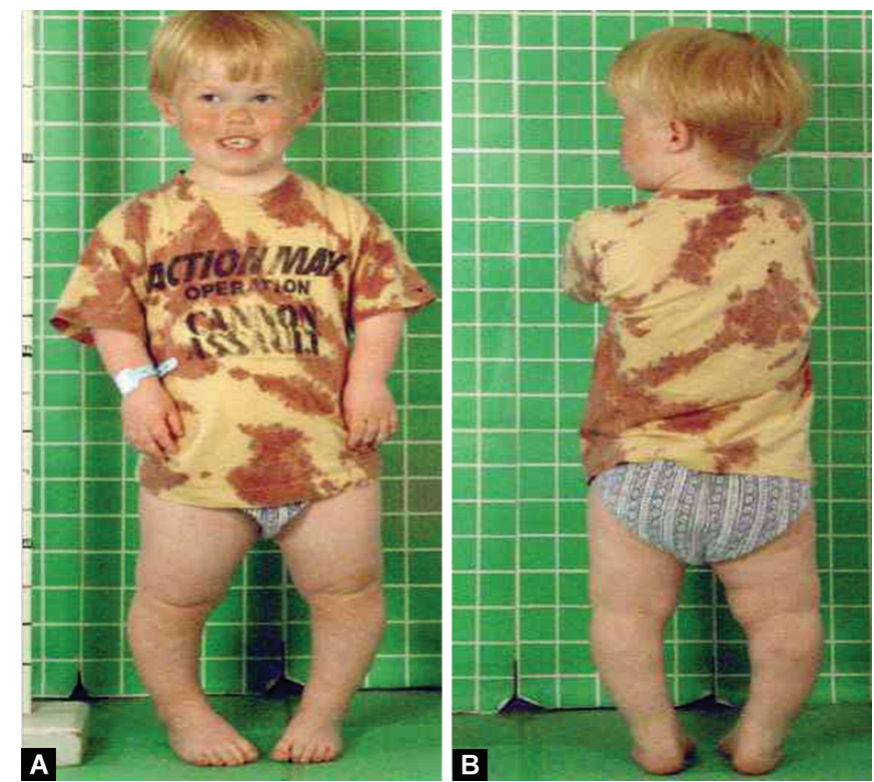

Figs $1 \mathrm{~A}$ and B: Case 1: Preoperative clinical picture

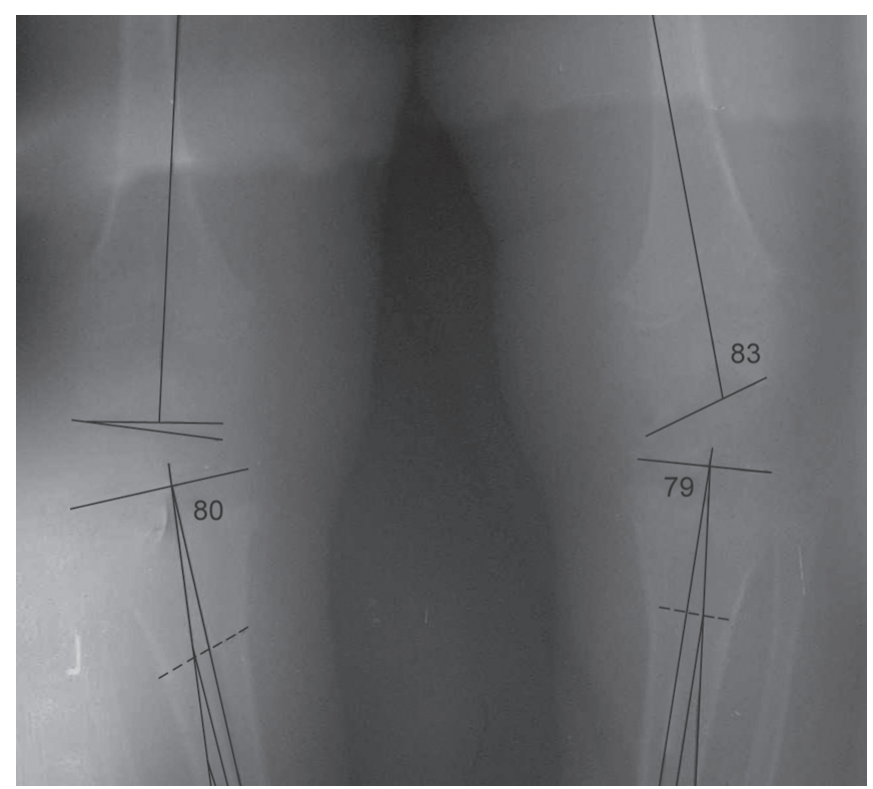

Fig. 3: Closeup view of the knee joints

We report the technique and early results of $L C L$ tightening in addition to bony realignment for genu varum in children with achondroplasia.

\section{Materials and Methods}

Between 1998 and 2003, 12 patients (24 limb segments) with achondroplasia and genu varum underwent realignment (with or without lengthening) of tibial deformities. There were 11 boys and 1 girl. The median age was 12 years 10 months (range 9-15 years 3 months). All patients had complained of joint instability (wobbly knees) and had chronic laxity of the LCL associated with frontal plane angular deformities of the tibia (with or without femoral involvement). Ligament laxity was graded using the American Medical Association grading system based on clinical examination: grade I: $0-5 \mathrm{~mm}$; grade II: $5-10 \mathrm{~mm}$; and grade III: $>10 \mathrm{~mm}$ of joint

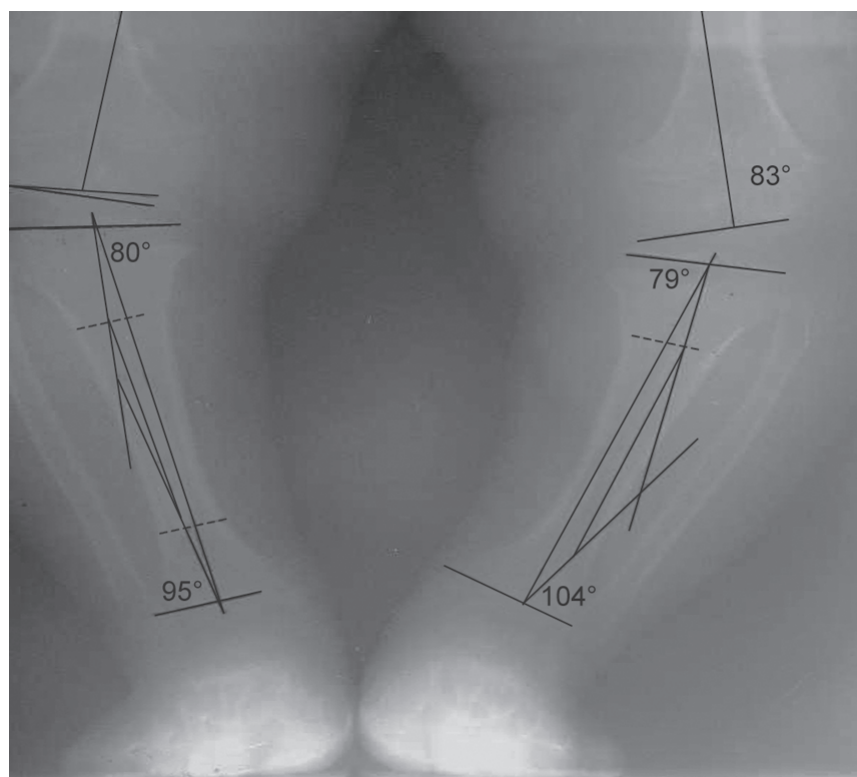

Fig. 2: Case 1: Preoperative planning X-ray

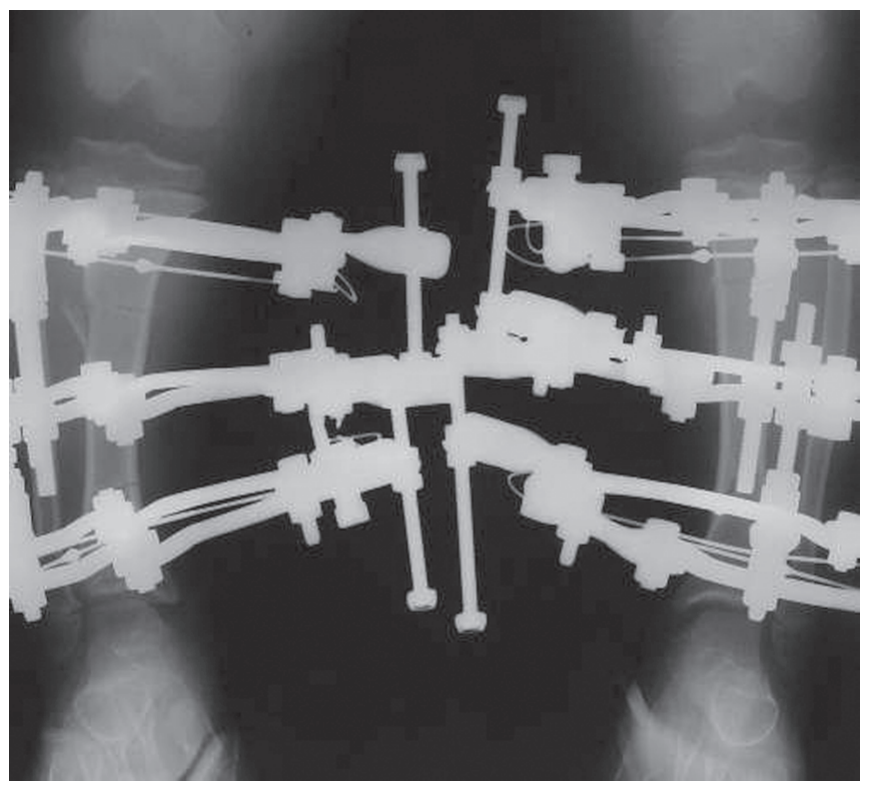

Fig. 4: Case 1: Postoperative X-ray

opening. All patients had grade III LCL laxity preoperatively and displayed an obvious lateral thrust during the stance phase of gait. Anteroposterior standing mechanical axis radiographs were obtained to evaluate frontal plane alignment and joint orientation pre- and postoperatively. Standing lateral views of both lower limbs were also obtained to assess sagittal plane alignment pre- and postoperatively.

Deformity analysis and correction planning were achieved using the malalignment and malorientation tests. The mechanical axis deviation (MAD) - measured as the distance from the limb mechanical axis to the centre of the knee-was documented before and after surgery. Other measurements included the medial proximal tibial angle (MPTA), the lateral distal femoral angle (LDFA), the joint line convergence angle (JLCA), and the distance of the proximal tip of the fibular head to the knee joint line before and 


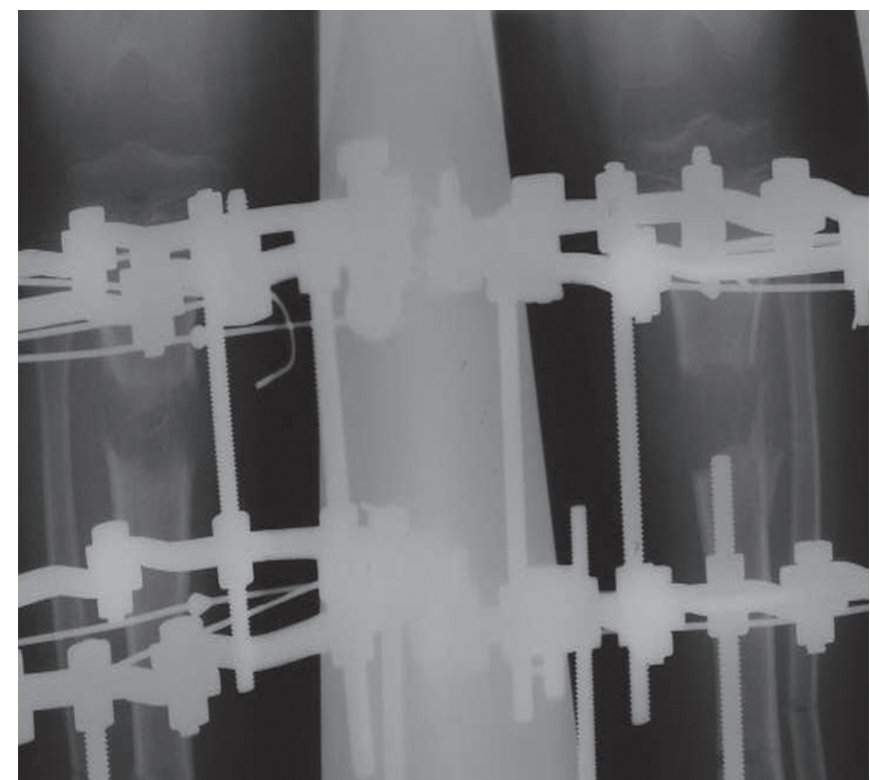

Fig. 5: Case 1: Follow-up X-ray with regenerate

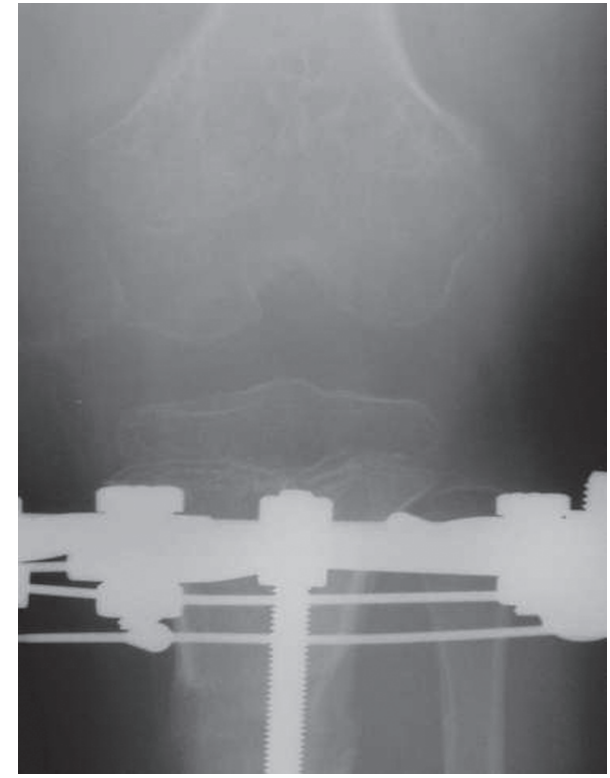

Fig. 7: Case 1: Post-lateral collateral ligament lengthening fibula at anatomical position

after surgery (F1 and F2). The difference between F1 and F2 was calculated as the vertical descent of the fibula.

The final outcome was graded based on a combination of subjective clinical and objective radiographic results using the grading system of Paley et al. ${ }^{12}$

\section{Surgical Technique}

All patients had bilateral corrections. The llizarov external fixator was used in 10 patients and the Orthofix limb reconstruction system (LRS, Orthofix SRL, Verona) in 2 patients. Bony realignment was achieved using monofocal or bifocal tibial osteotomies. Bifocal correction was performed in 13 segments and monofocal correction in 11 segments. The $\mathrm{LCL}$ was tightened in all limb segments using the Paley's type II strategy. ${ }^{12}$ The tibia was osteotomised initially

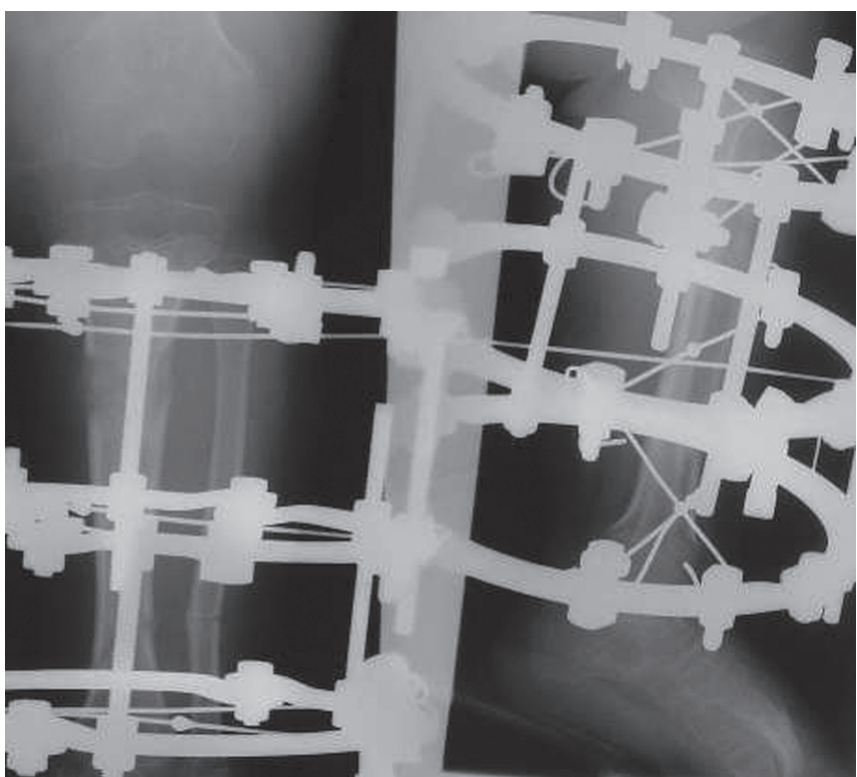

Fig. 6: Case 1: Consolidation of regenerate

without performing an associated fibular osteotomy. The tibia alone was held in the external fixator proximally (without transfixing the proximal fibula to the tibia), whereas, distal to the osteotomy, both the tibia and fibula were captured by the fixator wires or pins. Correction and lengthening of the tibia in the proximal osteotomy produces a distal movement of the entire fibula relative to tibia, without disruption of the ankle mortise, and a simultaneous tightening of the LCL. Once the lateral ligament has been tightened sufficiently to correct the JLCA, the fibula was then captured proximally in the fixator and a distal fibular osteotomy performed to enable further lengthening. Tightening was deemed complete when the fibular head had descended to the level of the tibial physis or when the JLCA had been overcorrected (Figs 8 to 13).

The postoperative management involved pain relief, pin site care, physiotherapy, occupational therapy, and has been previously described.

\section{Results}

\section{Clinical}

There were 20 limb segments graded as excellent and 4 as good. The patients were pleased with the outcome of the combined tibial realignment procedure with $\mathrm{LCL}$ tightening. The preoperative deformity, instability, and lateral thrust during the stance phase of gait had improved in all patients with the LCL laxity eliminated in all. No clinically significant recurrent instability was noted in any of the patients in the excellent group, but some stretching out of the ligament to a minor degree with time was seen. The median follow-up period was 41.5 months (range 15-96 months). The median fixator time was 160 days (range 95-384 days) and median time to fibular osteotomy was 27.5 days (range 20-42 days) (Table 1).

\section{Radiological}

The normal position for the mechanical axis is 1-15 mm medial to the centre of the knee. All patients had medial deviation of the mechanical axis well beyond normal before surgery. The preoperative median MAD was $34.5 \mathrm{~mm}(28-48 \mathrm{~mm})$ and was corrected to a median of $5 \mathrm{~mm}$ (range $0-15 \mathrm{~mm}$ ) postoperatively 

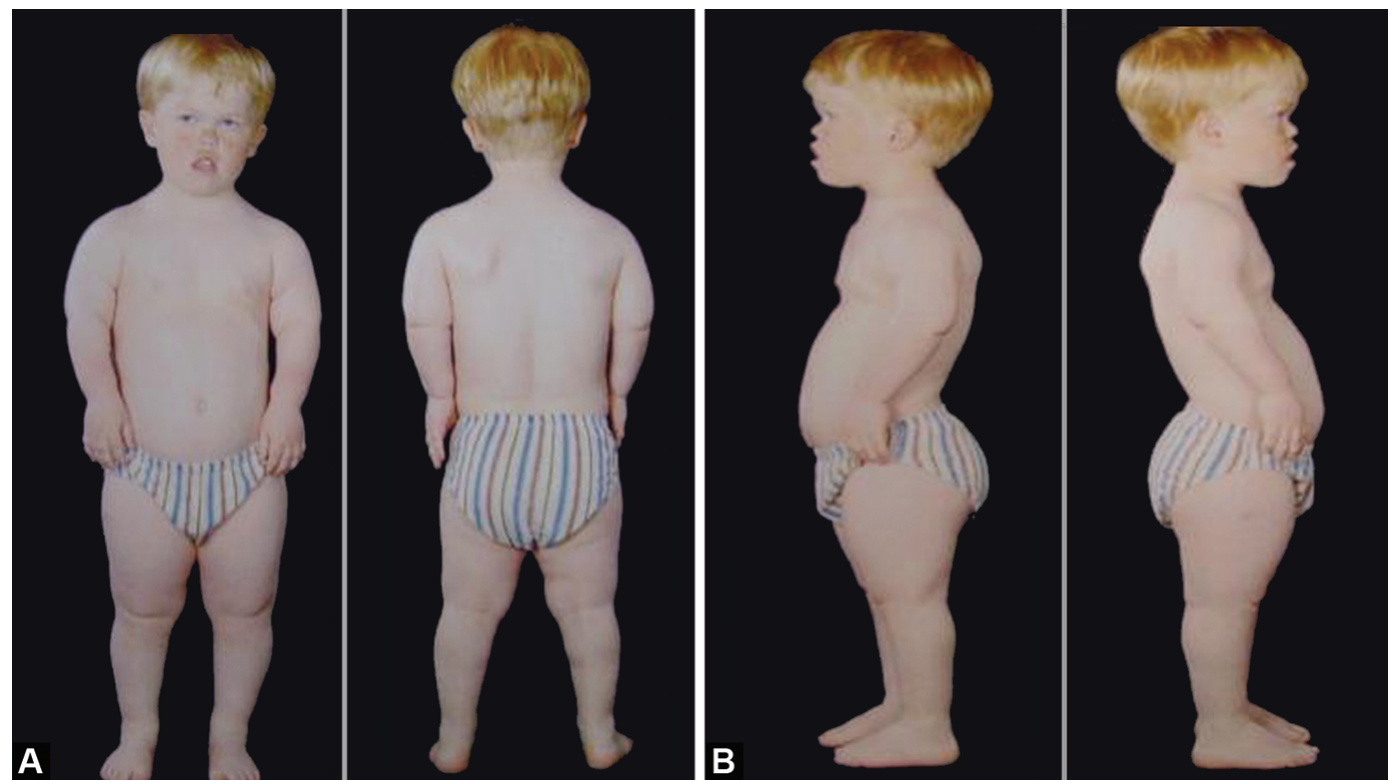

Figs $8 \mathrm{~A}$ and B: Case 1: Final clinical picture

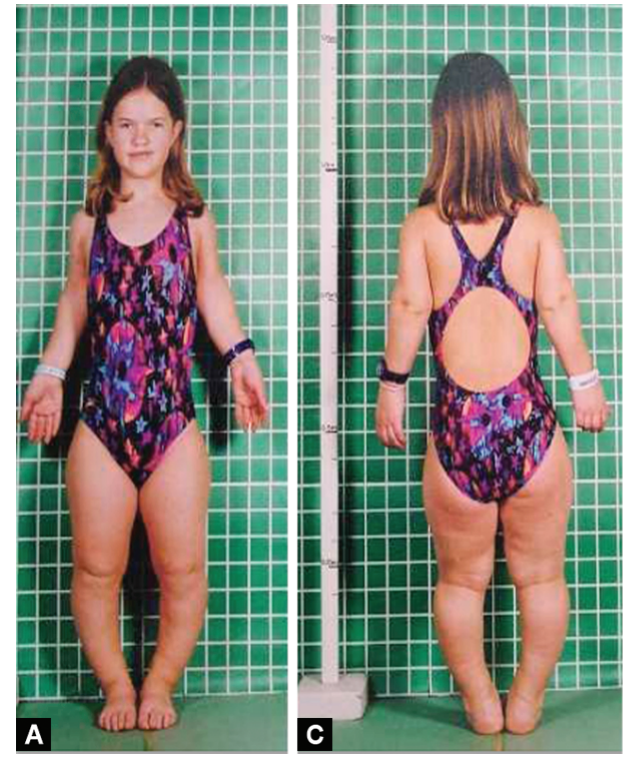

Figs 9 A to C: Case 2: Preoperative clinical picture
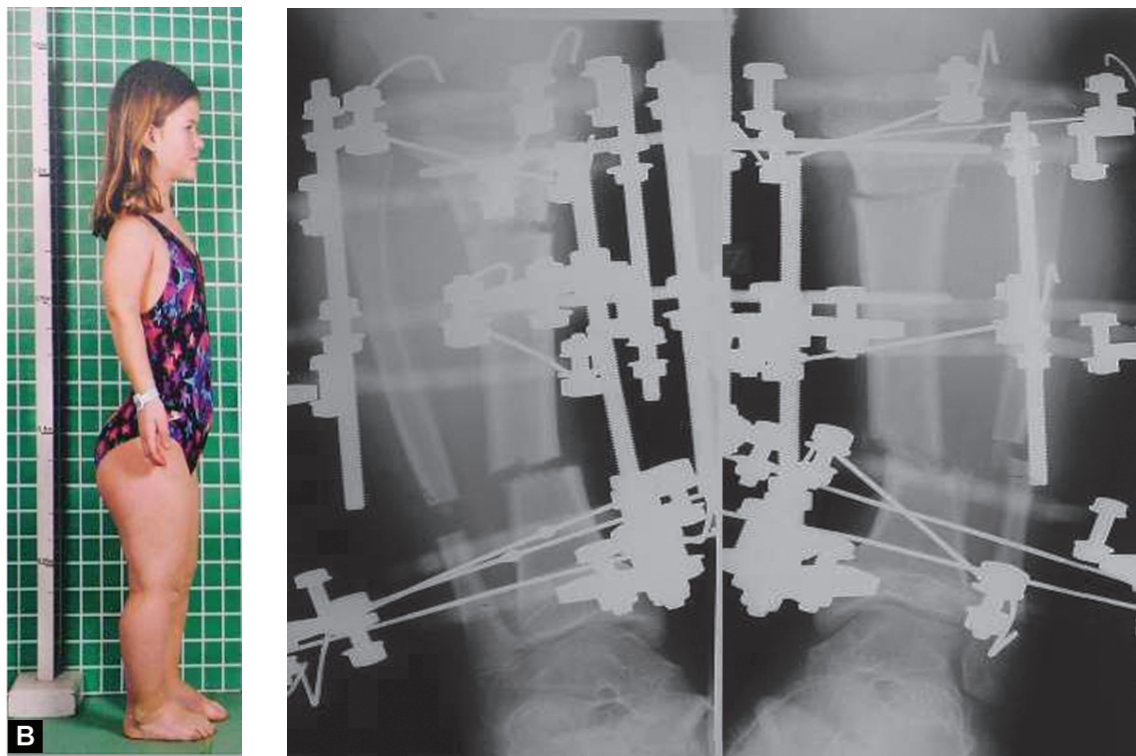

Fig. 10: Case 2: Postoperative X-ray

period. Four patients developed grade II pin site infections that were treated with oral antibiotics and rigorous pin site care. Premature consolidation of the tibial regenerate necessitated a repeat osteotomy in one patient. No proximal fibular physeal separation was observed in this series (Table 3 ).

\section{Discussion}

Frontal plane malalignment can result in excessive and asymmetrically loaded compartments of the knee joint. During single-leg stance, $75 \%$ of the knee joint load passes through the medial tibial plateau in the normally aligned knee. This is due to the medial location of the centre of gravity relative to the knee. Significantly, large medial and lateral MAD are thought to be associated with the possibility of late degenerative changes. This may be a function of the amount of MAD and the load applied 


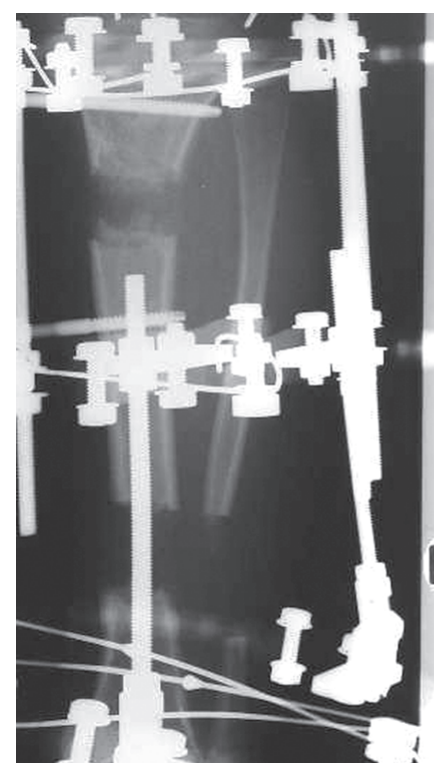

Fig. 11: Case 2: Post-correction

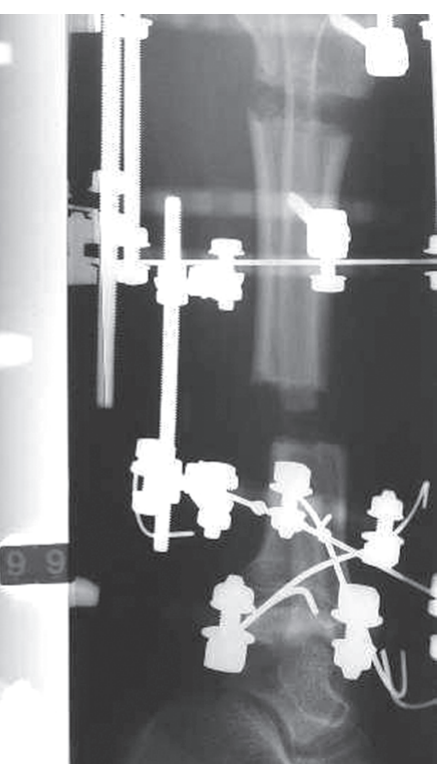

Fig. 12: Case 2: Final X-ray-fibula in anatomical position

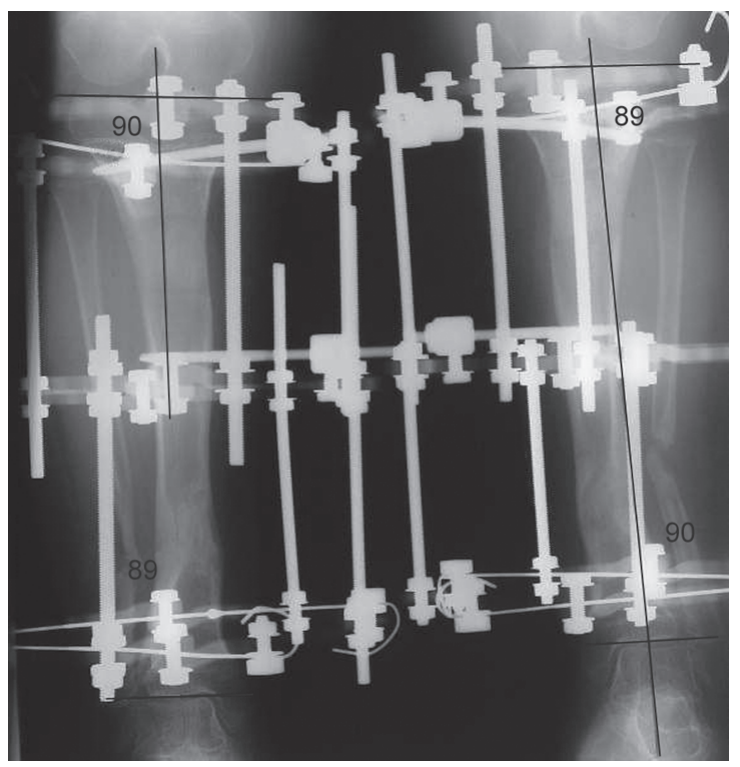

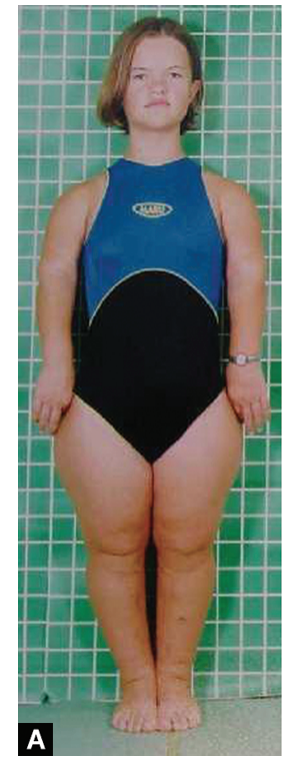
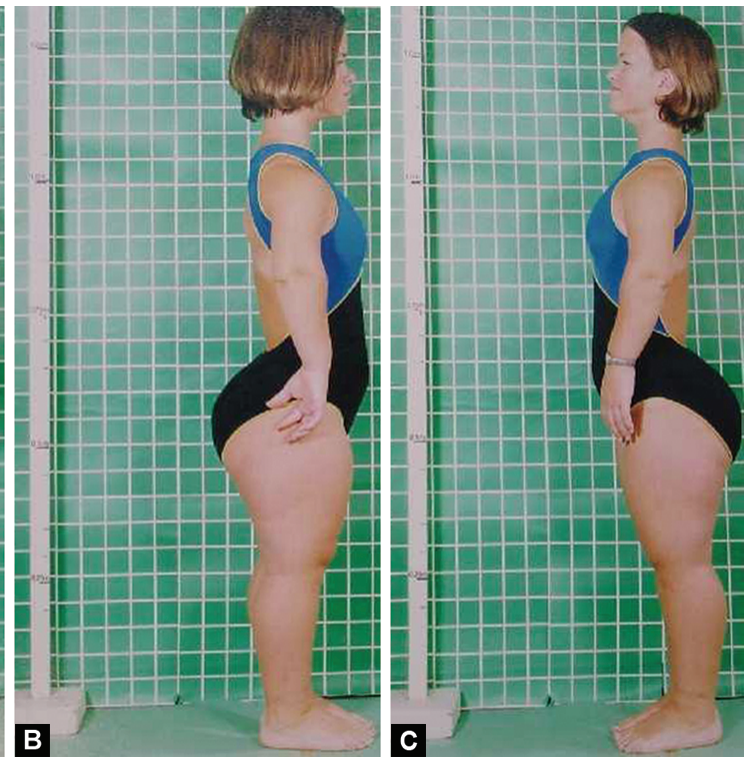

Figs $13 \mathrm{~A}$ to $\mathrm{C}$ : Case 2: Final clinical picture

to the knee and therefore affected by the patient's weight and activity level.

Mechanical axis deviation is usually attributed to tibial or femoral deformities or both. It is less often recognised as a result of ligamentous laxity between the tibia and femur. The closer a bony deformity is to the knee, the greater is the MAD produced per degree of angulation. Angulation due to collateral ligament laxity therefore produces the greatest amount of MAD per degree of angulation. Even small degrees of ligamentous laxity can produce large amounts of MAD.

The normal horizontal shear forces on the knee are under $10 \%$ bodyweight (5\% bodyweight medial shear and $7 \%$ bodyweight lateral shear). An increase in horizontal shear forces, amplifying joint instability, may increase the risk for degenerative changes. Laxity of the collateral ligaments leads to increase in the horizontal shear forces on the knee joint. This is perhaps the strongest argument for collateral ligament retensioning. When correcting lower extremity malalignment, the ligamentous component must be considered. Paley et al. have shown that collateral ligament tightening is a safe adjunctive procedure to bony realignment surgery resulting in a greater degree of correction for the same amount of surgery without significantly increasing the risks. ${ }^{12}$

Bowleg deformity has been observed in $50-60 \%$ of children with achondroplasia. ${ }^{1,3-5,7}$ The bowleg deformity is caused by fibular overgrowth relative to the tibia both proximally and distally. This causes altered relationships of the tibia and fibula at the knee and ankle. A previous study has revealed that bowleg deformity in children $<6$ years is associated with overgrowth of the fibula proximally resulting in proximal tibial varus and LCL laxity. Children $>8$ years also develop progressive overgrowth of the distal fibula resulting in distal tibial varus. ${ }^{2,7}$ 
Table 1: Clinical parameters (preoperative /postoperative)

\begin{tabular}{|c|c|c|c|c|c|c|c|c|}
\hline \multirow[b]{2}{*}{ Pt.no } & \multirow[b]{2}{*}{ Age } & \multirow[b]{2}{*}{ Sex } & \multicolumn{2}{|c|}{ Bowleg deformity } & \multicolumn{2}{|c|}{ LCL laxity } & \multicolumn{2}{|c|}{ Lateral thrust } \\
\hline & & & Preoperative & Postoperative & Preoperative & Postoperative & Preoperative & Postoperative \\
\hline 1 & 10 years 2 months & M & Yes & No & Grade III & Grade I & Yes & No \\
\hline 2 & 14 years 4 months & M & Yes & No & Grade III & Grade I & Yes & No \\
\hline 3 & 14 years 6 months & M & Yes & No & Grade III & Grade I & Yes & No \\
\hline 4 & 10 years 5 months & $\mathrm{F}$ & Yes & No & Grade III & Grade I & Yes & No \\
\hline 5 & 14 years 1 month & M & Yes & No & Grade III & Grade I & Yes & No \\
\hline 6 & 14 years 8 months & M & Yes & No & Grade III & Grade I & Yes & No \\
\hline 7 & 13 years 7 months & M & Yes & No & Grade III & Grade I & Yes & No \\
\hline 8 & 9 years 11 months & M & Yes & No & Grade III & Grade I & Yes & No \\
\hline 9 & 15 years 3 months & M & Yes & No & Grade III & Grade I & Yes & No \\
\hline 10 & 10 years 10 months & M & Yes & No & Grade III & Grade I & Yes & No \\
\hline 11 & 9 years 1 month & M & Yes & No & Grade III & Grade I & Yes & No \\
\hline 12 & 12 years 2 months & M & Yes & No & Grade III & Grade I & Yes & No \\
\hline
\end{tabular}

Table 2: Radiological parameters (preoperative /postoperative)

\begin{tabular}{|c|c|c|c|c|c|c|c|c|}
\hline \multirow[b]{2}{*}{ Pt. no } & \multicolumn{2}{|c|}{ MAD (medial in $\mathrm{mm}$ ) } & \multicolumn{2}{|c|}{$\operatorname{MPTA}\left({ }^{\circ}\right)$} & \multicolumn{2}{|c|}{$J L C A\left(^{\circ}\right)$} & \multirow{2}{*}{$\frac{\text { LDFA }\left(^{\circ}\right)}{\text { Preoperative }}$} & \multirow{2}{*}{$\begin{array}{l}\text { VFD (in } \mathrm{mm} \text { ) } \\
8\end{array}$} \\
\hline & Preoperative & Postoperative & Preoperative & Postoperative & Preoperative & Postoperative & & \\
\hline $1 \mathrm{R}$ & 32 & 3 & 79 & 88 & 8 & 2 & 88 & 8 \\
\hline $1 \mathrm{~L}$ & 34 & 0 & 78 & 89 & 8 & 2 & 89 & 8 \\
\hline $2 \mathrm{R}$ & 30 & 5 & 82 & 90 & 8 & 2 & 91 & 6 \\
\hline $2 \mathrm{~L}$ & 34 & 3 & 80 & 92 & 8 & 2 & 92 & 8 \\
\hline $3 \mathrm{R}$ & 28 & 2 & 81 & 91 & 9 & 2 & 87 & 8 \\
\hline $3 L$ & 30 & 0 & 82 & 90 & 7 & 3 & 89 & 5 \\
\hline $4 \mathrm{R}$ & 48 & 15 & 80 & 91 & 16 & 2 & 94 & 13 \\
\hline $4 \mathrm{~L}$ & 46 & 12 & 82 & 91 & 14 & 2 & 94 & 12 \\
\hline $5 \mathrm{R}$ & 40 & 4 & 82 & 89 & 8 & 2 & 91 & 9 \\
\hline $5 \mathrm{~L}$ & 36 & 5 & 80 & 90 & 8 & 3 & 91 & 8 \\
\hline $6 \mathrm{R}$ & 34 & 13 & 81 & 92 & 9 & 2 & 94 & 7 \\
\hline $6 \mathrm{~L}$ & 35 & 12 & 80 & 91 & 9 & 3 & 94 & 5 \\
\hline $7 \mathrm{R}$ & 36 & 4 & 79 & 88 & 8 & 2 & 88 & 7 \\
\hline $7 \mathrm{~L}$ & 35 & 3 & 76 & 89 & 8 & 2 & 87 & 9 \\
\hline $8 \mathrm{R}$ & 32 & 3 & 81 & 86 & 8 & 2 & 92 & 5 \\
\hline $8 \mathrm{~L}$ & 34 & 4 & 80 & 87 & 8 & 2 & 91 & 5 \\
\hline $9 \mathrm{R}$ & 38 & 5 & 82 & 89 & 7 & 2 & 88 & 7 \\
\hline $9 \mathrm{~L}$ & 36 & 6 & 81 & 88 & 9 & 3 & 89 & 7 \\
\hline $10 \mathrm{R}$ & 34 & 5 & 82 & 87 & 9 & 2 & 92 & 8 \\
\hline $10 \mathrm{~L}$ & 36 & 6 & 80 & 86 & 8 & 2 & 91 & 6 \\
\hline $11 \mathrm{R}$ & 38 & 5 & 79 & 89 & 8 & 3 & 89 & 5 \\
\hline $12 \mathrm{R}$ & 34 & 4 & 78 & 88 & 8 & 3 & 88 & 9 \\
\hline $12 \mathrm{~L}$ & 34 & 3 & 80 & 90 & 8 & 2 & 89 & 9 \\
\hline
\end{tabular}

Bowleg deformity of the lower limbs may remain asymptomatic or can cause significant morbidity in this population. Symptoms, when present, are pain, knee instability, limitation of joint function, a waddling gait, problems with body image, and, rarely, osteoarthritis. The potential for osteoarthritis of the knee in adult life has been observed occasionally in the limited number of natural history studies undertaken in this population. ${ }^{1,5,8,10}$

Treatment of bow leg deformity remains controversial. The need for surgical correction of some lower limb deformities in achondroplasia is recognised but the specific criteria for treatment have not been established. Brace treatment has been suggested but data to support this treatment are not available at present. Surgical intervention may be necessary in 10-40\% of patients with genu varum. Fibular epiphyseodesis, fibular head resection, tibial and fibular valgus osteotomies, and bony realignment with $\mathrm{LCL}$ tightening have been suggested. $7,8,10,12$ The beneficial effects of fibular head resection and fibular epiphyseodesis are not yet proven. Mid-term results of valgus tibial and fibular osteotomies have been reported to be successful in this population. ${ }^{11}$ Based on his experience, Kopits has suggested that surgical correction be undertaken in patients with achondroplasia who have (1) significant malalignment at any age and (2) asymptomatic malalignment before completion of skeletal maturity. ${ }^{3,4}$ 
Table 3: Treatment and outcome parameters

\begin{tabular}{|c|c|c|c|c|c|c|c|c|}
\hline Pt.no & Strategy & $\begin{array}{l}\text { Fixator time } \\
\text { (days) }\end{array}$ & $\begin{array}{l}\text { FU period } \\
\text { (months) }\end{array}$ & $\begin{array}{l}\text { Deformity } \\
\text { correction }\end{array}$ & $\begin{array}{l}\text { Tibial } \\
\text { lengthening }(\mathrm{cm})\end{array}$ & $\begin{array}{l}\text { Patient } \\
\text { satisfied }\end{array}$ & Complication & Final outcome \\
\hline 1 & Bifocal/Ilizarov & 95 & 42 & Achieved & 3 & Yes & None & Excellent \\
\hline 2 & Monofocal/Ilizarov & 132 & 90 & Achieved & 4 & Yes & None & Excellent \\
\hline 3 & Bifocal/Ilizarov & 138 & 85 & Achieved & 4 & yes & Pin site infection & Excellent \\
\hline 4 & Bifocal/Ilizarov & 242 & 30 & Persisting DF varus & 8 & Yes & Pin site infection & Good \\
\hline 5 & Bifocal/Ilizarov & 105 & 24 & Achieved & 3 & Yes & None & Excellent \\
\hline 6 & Bifocal/Ilizarov & 145 & 24 & Persisting DF varus & 4 & Yes & None & Good \\
\hline 7 & Bifocal/Ilizarov & 241 & 66 & Achieved & 7 & Yes & $\begin{array}{l}\text { Transient } \\
\text { peroneal } \mathrm{N} \text { palsy }\end{array}$ & Excellent \\
\hline 8 & Bifocal/Ilizarov & 146 & 30 & Achieved & 4 & Yes & None & Excellent \\
\hline 9 & Bifocal/Ilizarov & 380 & 41 & Achieved & 8 & Yes & Pin site infection & Excellent \\
\hline 10 & Monofocal/Ilizarov & 224 & 15 & Achieved & 5 & Yes & None & Excellent \\
\hline 11 & Monofocal/LRS & 384 & 96 & Achieved & 9 & Yes & Pin site infection & Excellent \\
\hline 12 & Monofocal/LRS & 376 & 91 & Achieved & 8 & Yes & $\begin{array}{l}\text { Premature } \\
\text { consolidation } \\
\text { tibial regenerate }\end{array}$ & Excellent \\
\hline
\end{tabular}

Combined bony realignment with collateral ligament tightening has been shown to provide a greater correction for the same amount of surgery. This technique addresses both the static and dynamic components of the deformity. Collateral ligament tightening reduces the horizontal shear stresses on the knee during single leg loading and may contribute to knee joint preservation. Good results have been reported by Paley et al. at a mean follow-up of 1 year in a mixed group of patients. ${ }^{12}$

\section{Conclusion}

This is a retrospective study of children with achondroplasia with bowleg deformity treated by bony realignment and LCL tightening. Surgery with uni- or bifocal tibial realignment and a type II collateral ligament tightening was performed. The tibia was lengthened differentially in relation to the fibula by an amount sufficient to allow realignment and LCL tightening. The lateral ligament laxity that had contributed to more than $40 \%$ of the MAD in this series was improved to within normal range. Excellent to good results were achieved in all patients without major complications.

\section{References}

1. Shapiro F. Skeletal dysplasias. In: Paediatric lower limb deformities 2001. pp. 733-871.

2. Ponseti IV. Skeletal growth in achondroplasia. J Bone Joint Surg 1970;52-A(4):70. DOI: 10.2106/00004623-197052040-00004.
3. Kopits SE. Orthopaedic complications of dwarfism. Clin Orthop 1976;114(114):153-179.

4. Kopits SE. Genetics clinics of the John Hopkins hospital. surgical intervention in achondroplasia. Correction of bowleg deformity in achondroplasia. Johns Hopkins Med J 1980;146(5):206-209.

5. Bailey JA. Orthopaedic aspects of achondroplasia. J Bone Joint Surg 1970;52-A(7):1285-1301. DOI: 10.2106/00004623-197052070-00001.

6. Hunter AG, Bankier A, Rogers JG, et al. Medical complications of achondroplasia: a multicentre patient review. J Med Genet 1998;35(9):705-712. DOI: 10.1136/jmg.35.9.705.

7. Stanley G, McLoughlin S, Beals RK. Observations on the cause of bowlegs in achondroplasia. J Pediat Orthopaed 2002;22(1):112-116. DOI: 10.1097/01241398-200201000-00023.

8. Haga N. Management of disabilities associated with achondroplasia. J Orthop Sci 2004;9(1):103-107. DOI: 10.1007/s00776-003-0729-4.

9. Yasui $\mathrm{N}$, Kawabata $\mathrm{H}, \mathrm{Kojimoto} \mathrm{H}$, et al. Lengthening of the lower limbs in patients with achondroplasia and hypochondroplasia. Clin Orthop 1997;344(344):298-306. DOI: 10.1097/00003086-199711000-00030.

10. Saleh $M$, Burton $M$. Leg lengthening: patient selection and management in achondroplasia. Orthopedic Clinics of North America 1991;22(4):589-599.

11. Laurencin CT, Ferriter PJ, Mills MB. Oblique proximal tibial osteotomy for the correction of tibia vara in the young. Clin Orthop Rel Res 1996;327:218-224. DOI: 10.1097/00003086-199606000-00027.

12. Paley D, Bhatnagar J, Herzenberg JE, et al. New procedures for tightening knee collateral ligaments in conjunction with knee realignment osteotomy. Orthopedic Clinics of North America 1994;25(3):533-555. 